\title{
Don't Laugh at the Comics: a Modern Take
}

\author{
Ryan C. W. Hall ${ }^{1}$. Susan Hatters Friedman ${ }^{2}$
}

Received: 13 January 2020 / Accepted: 2 June 2020/Published online: 1 July 2020

(C) Academic Psychiatry 2020

A surprising number of mental health providers are villains in comic books, many of whose origins date back to the 1940s. One only needs to look at Batman's Rogues Gallery from that time (Dr. Hugo Strange, psychiatrist/ psychologist created in 1940; Dr. Jonathan Crane, a.k.a. the Scarecrow, psychologist created in 1941; and Jervis Tetch, a.k.a. the Mad Hatter, neuroscientist created in 1948) to realize that mental health providers are not always portrayed in the best light [1]. This raises the question whether this negative representation has potential real world impact regarding mental health stigma and how mental health providers are perceived [2]. One theory about why there is such a negative representation of mental health in comic books is that it is a response to the concerted effort by some mental health professionals in the 1940s and 1950s to regulate and ban comic books $[3,4]$. This effort culminated in Senate hearings in 1954 to determine whether comic books contributed to juvenile delinquency [4]. Historians often refer to this time period as the " 10 cent plague" or the "comic book moral panic" of the 1950s [4]. Reverberations are still felt today (e.g., legacy characters, such as Dr. Strange, being key players in TV shows such as Gotham) but there is beginning to be a shift in how comics portray mental illness and how mental health providers can use the messages and stories from comics for teaching. Considering that comics are roughly a 1-billion-dollar business in North America and sold primarily to adolescents and adults across multiple locations (comic book stores, traditional book stores, and digital downloads), how psychiatrists and psychiatric conditions are portrayed in comics impacts more than just children [5].

Ryan C. W. Hall

rcwh@live.com

1 University of Central Florida, Orlando, FL, USA

2 Case Western Reserve University, Cleveland, OH, USA

\section{The Potential for Comics to Be Used for Good: Teaching}

Before delving too deeply into the interaction between comic books and mental health, it is important to note that there are plenty of examples of mental health and medicine in general, using storytelling and comic books specifically for positive outcomes and teaching [6]. Going back to the earliest days, psychiatry has looked to entertainment as one way to teach about concepts, such as Freud's use of the Greek tragedy, Oedipus, to describe unresolved conflicts in relationships. In the mid-1950s, a comic book entitled Psychoanalysis even attempted to teach the general public about the powerful transformations that can come from mental health treatment [6]. Unfortunately, the series only lasted four issues and was financially unsuccessful. In more recent years, health departments have used comic books to teach and appeal to younger populations such as the CDC's comic book Preparedness 101: Zombie Pandemic or the Canadian Public Health publication A Winning Run is Scored Over Diabetes [6].

It has been noted that many forms of pop culture (e.g., movies, tv shows, books, comic books) can be used to teach mental health concepts, whether to medical students or in the therapy room $[2,7]$. For example, we previously wrote about using characters and ideas from the Star Wars Universe to teach various psychotherapeutic concepts [7].

Of note, whenever popular culture is used to facilitate learning (e.g., using a hypothetical example to start a deeper discussion), care needs to be taken to make sure educational activities stay focused on topic, and the topics themselves are not trivialized. For instance, an interesting group discussion was held in a class for a course on law and psychiatry about whether Bruce Banner was culpable for damage done when his rage transformed him into the Hulk. This led to an abstract case discussion that covered medico-legal concepts such as mitigation, causation, actions taken in "hot blood," appropriate treatment and oversight, and diagnostic concerns (e.g., is the Hulk's condition intermittent explosive disorder, an anxiety condition, or dissociative identity disorder). However, the professor did need to refocus the discussion off of tangential 
topics such as unrelated movies and who would win in a fight between the Hulk and the Thing (see Table 1 for additional ways comic books can be used to discuss various mental health concepts).

When discussing psychopathology in a galaxy far, far away, we noted that in order for pop culture to be an effective teaching tool, it needs to be relevant, timeless, universal in scope, well known, and incorporated in shared culture enough that it can become a shorthand for everyday problems or experiences [7]. Considering that the "modern day" comic book industry has been around since 1935 [1, 2, 4], and that comic books and their subsequent portrayal in other media (television, movies, and video games based on comics) are well known to the general population, there is no reason to believe that comic books do not have an impact on our patients' perspectives - either positively or negatively. Access to back issues is now easier than ever to obtain due to publishers having digitized their catalogs. This makes exposure to positive storylines, but also negative stereotypes from the 1940s easier to access than ever.

\section{Pros and Cons of Comic Books as Seen by Mental Health}

Although comic books may be used to educate the lay public and medical students, the comic book industry and mental health fields have often had a tumultuous relationship — which unfortunately can also yield the opposite result of perpetuating stigma. A lot of this stems from when some mental health professionals and parent groups expressed concerns that comic books were causing juvenile delinquency in the 1940s [4]. The figurehead for this movement was the psychiatrist Dr. Fredric Wertham, who testified in front of the aforementioned Senate Subcommittee Hearings into Juvenile Delinquency about crime and horror comic books [3]. Wertham's concern was that the graphic representations of sex, violence, and crime in comic books could send the wrong messages to children, which would negatively impact their psychological and moral development (e.g., Superman punching criminals teaches that problems can be solved with violence). His objections often came across as dramatic and authoritative in testimony:

Formerly to impair the morals [of] a minor was a punishable offense. It has now become a mass industry. I will say that every crime of delinquency is described in detail and that if you teach somebody the technique of something you, of course, seduce him into it. Nobody would believe that you teach a boy homosexuality without introducing him to it. The same thing with crime.... It is my opinion, without any reasonable doubt, and without any reservation, that comic books are an important contributing factor in many cases of juvenile delinquency. There arises the question: What kind of child is affected? I say again without any reasonable doubt and based on hundreds and hundreds of cases of all kinds, that it is primarily the normal child [3].

Wertham's advocacy had a profound impact on the comic industry with his work leading to an attempt to ban the importation of US comics into several countries (including Canada), and the Comic Magazine Association of America instituting the restrictive Comics Code Authority as a way to avoid governmental censorship [4]. The comic book industry was one of the first media types, if not the first, to self-regulate since the Comic Code predates the Motion Picture Association of America rating system (1968), the Recording Industry Association of America warnings (1985), and the Entertainment Software Rating Board (1994) [4].

Although some in the mental health field in the 1940s and 1950s did discuss how comic books could be beneficial for treating or presenting ideas, they did not have the impact that Wertham had. Most notably discussing the benefits of comics were psychologist Dr. William Moulton Marston and child neuro-psychiatrist Dr. Lauretta Bender (who is also known for the Bender-Gestalt psychological test) [8-11]. Dr. Marston, along with being a co-creator of Wonder Woman, wrote scholarly articles defending the potential positive impacts of comics such as Why 100,000,000 Americans Read Comics [8] and was the subject of pieces such as Don't Laugh at the Comics [9]. Dr. Bender authored the paper The Effect Of Comic Books On The Ideology Of Children [10] based on her experiences working with children and sometimes using comic books to better understand their mental state. However, given some of the details of Dr. Marston's personal life, as recently sensationalized in the film Professor Marston and the Wonder Women (e.g., polyamory), many questioned his character rather than his arguments, when it came to the potential harms of comics to children [4].

Dr. Bender, in the 1950s, was a pioneer in childhood mental health theory, and eventually testified in front of the Senate panel regarding the potential positive effects of comic books [11]. In her testimony, she made statements such as:

In my early years in working at Bellevue Hospital when we were hard put to find techniques for exploring the child's emotional life, his mind, his ways of reacting, when the child was separated from the home and brought to us in the wards at Bellevue, I found the comics early one of the most valuable means of carrying on such examinations, and that was the beginning of my interest in the comic books.... In adult psychiatry, dreams are analyzed, [for children comic books] [11].

However, given that Dr. Bender had started to work with DC Comics editorial advisory board for the Superman Comics, her opinion was minimized by some [4]. 
Table 1 Comic book hero stories that can be used to teach mental health concepts

\begin{tabular}{|c|c|}
\hline Psychopathology & \\
\hline Condition/symptom & Character/issue \\
\hline Bipolar & $\begin{array}{l}\text { Hank Pym "Initiate: Chapter 5" } \\
\text { Avengers A.I. (2013) }\end{array}$ \\
\hline Depression & Daredevil \#10 (2014) \\
\hline $\begin{array}{l}\text { Post-Traumatic Stress } \\
\text { Disorder }\end{array}$ & Jessica Jones: Alias (2001-2004) \\
\hline Delusions & Wonder Woman \#15 (2017) \\
\hline "Psychotic Break" & Scarlet Witch in House of M (2005) \\
\hline $\begin{array}{l}\text { Obsessive compulsive } \\
\text { disorder }\end{array}$ & Batman in Heroes in crisis (2016) \\
\hline Schizophrenia & $\begin{array}{l}\text { Sentry, multiple story lines } \\
\text { (e.g., Sentry } 1-5(2000))\end{array}$ \\
\hline $\begin{array}{l}\text { Dissociative identity } \\
\text { disorder (DID) }\end{array}$ & $\begin{array}{l}\text { Several story lines for the character } \\
\text { Legion (e.g., new Mutant 26-28, 1985) } \\
\text { and Moon Knight (e.g., Birth and death story) }\end{array}$ \\
\hline $\begin{array}{l}\text { Phobias and panic } \\
\text { attacks }\end{array}$ & $\begin{array}{l}\text { Storm, in several X-men stories } \\
\quad \text { (e.g., Uncanny X-Men \#102 (1976)) }\end{array}$ \\
\hline $\begin{array}{l}\text { Differential diagnosis } \\
\text { and cultural } \\
\text { phenomena }\end{array}$ & $\begin{array}{l}\text { Several Wolverine storylines } \\
\quad \text { (e.g., Uncanny X-Men \#96, (1975)) }\end{array}$ \\
\hline
\end{tabular}

Teaching points*

Aspects of bipolar disorder and individuals coming to acceptance of their symptoms

Graphic representation of loneliness, feelings of isolation, and despair

Aspects of symptoms, behavior, and coping mechanisms (positive and negative)

Question of "psychotic/nervous breaks" and the importance of obtaining an adequate history to determine truth vs delusion

Notion of fantasy worlds as a way to cope with pain

Though Batman could have complicated grieving, depression, or PTSD, here for the man who plans for everything, the discussion point is to consider if he has OCPD or a form of OCD

Another character with multiple diagnoses, of schizophrenia, $\mathrm{GAD}$, and agoraphobia. Discussion point is although frequently identified as schizophrenia, how he is represented is more consistent with DID. In addition, story lines include a generally positive relationship with his psychiatrist Dr. Cornelius Worth.

Addressing the representation in comics to what the condition is really like

The nature of how debilitating a panic attack can be and how irrational a phobia can be

Bezerker rage: is it intermittent explosive disorder; is it akin to the cultural concept of amok or blood rage; is it a true dissociative fugue state; or is it an example of impulsivity as seen with antisocial personality disorder?

\section{Description}

Shows nature of therapeutic relationship and how it often takes time to build trust and to make change

Discussion of medication and nature of illness and why it is important to engage in treatment

Highlights coping techniques such as humor, denial, repression, cognitive dissonance, avoidance

Long-term effects of chronic trauma with potential analogies to high functioning groups such as police, fire, and military (e.g., PIES model of trauma treatment historically used by military)

Teaching points

Highlights pathology of abusers and co-dependent nature of some relationships

Highlights reactions of others to abuse and potential characteristics of abusers

Brief one pager which highlights empathy and understanding for others

Shows aspects of grieving and ways individuals cope with loss of a loved one or child

Can highlight aspects of extreme political philosophies and how individuals justify their actions. 
Table 1 (continued)

Adjusting to illness

Suicidal Ideation

Forensic issues

Sub-topic

Family murder

Involuntary

commitment

Insanity/forensic

psychiatric treatment

Mitigation/tort law

concepts

Substance use disorders

Condition

Alcoholism

Opioid addiction

Anabolic Steroid Abuse

Methamphetamine

Cocaine (or

representation thereof)

Prescription Pills Abuse
Eddy Broke Hunger storyline in the

Spectacular Spiderman (203)

Deadpool World's Greatest \#20 (2015)

The Never-ending Struggle

Character/issue

Arkham Asylum, a Serious House on a Serious

Earth

"Rendered" Moon Knight \#11 (2014).

Deadpool Initialization store line (2011)

and Multiple Arkham Asylum focused

stories and Ravenscroft Stories

Incredible Hulk multiple story lines

Character/issue

"Demon in the Bottle" The invincible

Iron Man \#128 (1979)

"Snowbirds Don’t Fly" Green Arrow/Green

Lantern \#85-86 (1971)

"Batman Venom" Batman: Legends

of the Dark Knight \#16-20 (1991)

"Streets of Poison" Captain America

\#372-378 (1994)

Ultraman in Forever Evil storyline (2013)

“The Bottom” Moon Knight \#1 (2006)
Dealing with negative effects of physical health problems

such as cancer

Can lead to a discussion about misconceptions related to

suicide and how to properly obtain help

Discussion

Specifically addresses matricide

Discussion related to how civil commitment and forced medication are depicted

Discussion related to insanity defense, nature of forensic

hospital treatment, and maintaining professional boundaries

Is Bruce Banner criminally or civilly responsible for damage that he/the Hulk inflicts?

Teaching points

Leads to discussion of symptoms of alcoholism and effects on relationships

Historic example of how Heroin addiction is detected and people believe could not happen to their family

Allows for discussion on motivation and effects of using anabolic steroids

Discussion related to methamphetamines and accidental exposure to substances

Shows addictive nature of substances, lengths people may go to continue using, and perceived euphoric effects

Demonstrates prescription pill abuse after physical injury and patterns that can occur such as mixing with alcohol

* Characters, comics, and teaching points identified are only meant as possible examples of topics that can be discussed and used as examples. The table is not meant to be a definitive list

Although some themes have changed, some in the mental health community still voice concerns regarding comic book characters and the imagery they portray. In Wertham's day, there were concerns related to violent fantasies as found in the Superman mythos, sadomasochism as depicted in Wonder Woman, and homosexuality in Batman-which in today's world have been replaced with concerns regarding toxic masculinity and objectification of females $[3,4,12]$. For example, in 2010 at an American Psychological Association meeting, a lecture about how modern-day comic book heroes, such as the film version of Iron Man, "exploited women, flaunted bling, and conveyed their manhood with high-powered guns" was presented [12]. Speakers criticized that the characters of today did not measure up to the characters of the Golden Age, "[who] did fight criminals, but [were] heroes boys could look up to and learn from because, outside of their costumes, they were real people with real problems and many vulnerabilities" [12]. Just as some criticized Wertham for not actually knowing the media he was critiquing, the same concern could be raised for some of the modern criticism [11]. For example, Iron Man had a famous storyline of vulnerability called Demon in a Bottle in 1979, which related to his struggles with alcoholism. Both substance abuse treatment sites and comic book sites have referenced this story as a significant event in comics that encouraged people to seek help for alcoholism $[13,14]$. It was even rumored that aspects of that storyline would be incorporated into Iron Man 3, but the decision was made to go with PTSD instead as part of Iron Man's character arc. This raises the point that fictional characters have weaknesses and flaws to overcome, in order to grow and demonstrate change (e.g., spoiler, Tony Stark, a.k.a. Iron Man, went from a misogynistic self-absorbed arrogant playboy to selfsacrificing family man). Although it is important for the mental health community to help identify concerning negative portrayals [1] and work with the media to minimize potential harmful impacts (e.g., the portrayal of suicide in 13 Reasons Why was suspected of causing a spike in suicides, resulting in changes in the show), it is also sometimes desirable to let fictional characters develop or be a vehicle for social commentary $[2,15]$.

\section{Lost Opportunity and Stigma}

The Comics Code famously prevented the Spiderman creator, Stan Lee, from addressing the drug problem in the 1960s [16]. 
However, in 1971, Lee wanted to make reference to the negative impacts of drugs, so he published Issue 96-98 of The Amazing Spiderman without the Comics Code Authority logo. Some of the dialog which referenced drug use that was felt to go against the Code included:

Spiderman: Any drug strong enough to give you that kind of trip can damage your brain but bad. But how do you warn the kids? How do you reach them? My life as Spiderman is probably as dangerous as any, but I'd rather face a hundred supervillains than toss it away by getting hooked on hard drugs 'cause that's one fight you can't win [17].

This led to DC comics also having storylines showing the negative impact of drug use. In 1971, DC published a Green Arrow comic where Green Arrow learns that his ward, Speedy, has a heroin addiction [16]. Due to the overall positive reception of these comics and storylines denouncing drug use, the Comics Code Authority content prohibition started to change and was eventually abandoned [16].

Even though comic books were willing to address societal ills in the 1970s, they still often portrayed psychiatrists and therapists negatively. This can famously be seen in the 1964 Amazing Spiderman \#13, where Spiderman was believed to be the first superhero to voluntarily seek out psychiatric help (spoiler, the villain Mysterio was using special effects to make Spiderman think he was mentally ill). The dialogue in the panel between Spiderman and the psychiatrist goes as follows:

Psychiatrist: (Italics represented in thought bubble) Spider-man! If I can make a patient out of him, I'll make medical history. Imagine a mysterious super-hero who is a mental case! I think I can help you. Just come down from that wall and lie down on the couch. I'll try to probe into your subconsciousness. Don't be nervous.

Spiderman: Ok, doc, but no tricks here [18].

Even when doctors were trying to be helpful, they were still portrayed as being devious, not to be trusted, not understanding what was really going on, and never being able to provide answers or to help the superheroes who sought them out. It is unlikely that a comic book character would go to any other health provider in a state of need, and tell them "no tricks."

In addition to the blatantly evil psychiatrists and the narcissistic psychiatrists, since the late 1970s, there have been character representations of the flawed or damaged (psychiatric) hero. In the Marvel universe, this is typified by the character of Doc Sampson (who, according to the Marvel website [19], has a "PhD in psychiatry"), and more recently in the DC Universe Dr. Kent Nelson (one of the vessels for Dr. Fate) [1]. Doc Sampson was originally introduced in the 1970 s as part of the Incredible Hulk storyline where, despite being well-meaning, he initially worked with the villain General Ross. With time, Doc Sampson has had some heroic turns, but also has had villainous turns such as when he was part of the criminal super-agency "Intelligencia." Kent Nelson was a successful psychiatrist until his professional reputation was destroyed by having an affair with a student, which resulted in him losing his family, and suffering from depression. It was in this state that he came across the magic helmet that allowed him to become a vessel for the hero Dr. Fate.

Although one can argue that the representation of mental health professionals is just classic storytelling tropes that are no different than how other professionals (e.g., the corrupt police officer) or demographic groups (e.g., the damsel in distress) are portrayed, they are still potentially harmful in that they exacerbate stigma and discourage people seeking help [2]. Even the once revered Dr. Amadeus Arkham, founder of Arkham Asylum, becomes a warning about psychiatric care after he kills patients, murders his mother, and becomes an inmate in the institution he founded, in a 1989 graphic novel story line [20]. Negative representations of psychiatrists in fiction are not unique to comics, occurring in books and films as well (e.g., Hannibal Lecter being a Dr. Evil archetype) [2, 21]. Although it may be a common fictional trope, it is still concerning. As seen from the MacArthur Foundation's research, for those with mental illness being actively engaged in treatment is actually one of the best ways to reduce violence for the individual and for society [22]. Although comics and fiction may not be able to fully give up negative representations of psychiatrists, it is hoped that established characters can be given nuance or allowed to grow. This did occur for Amadeus Arkham who did have a better depiction in All-Star Western comics in 2011 as more of a heroic side kick [1].

\section{A New Beginning?}

Within the last decade, mental health professionals and comic book creators have occasionally worked together. Some storylines involved established characters such as Marvel's Daredevil dealing with depression and DC's Heroes in Crisis event addressing the effects of trauma [14, 23]. New characters such as Silk from the Spiderman Universe and The Unstoppable Wasp have had positive interactions with mental health treaters [23-25]. These positive interactions can be helpful for fighting stigma as well as being teaching aids. Both comics showed superheroes voluntarily seeking treatment, 
engaging in positive psychotherapy relationships over multiple issues, and in the case of The Unstoppable Wasp, even benefitting from medications [23-25]. The interaction between the Wasp and her psychiatrist Dr. Sinclair highlights how comics can educate about mental health and treatment without disrupting the overall story or arc of the character. The Wasp states to Dr. Sinclair "I am sick and I need your help to get better," to which the doctor responds "With medication and mindful behavior we can manage [Bipolar] and we can minimize the impact" [25]. This is a far cry from the "no tricks doc" of the early Spiderman.

There are likely many reasons that comic books at some level are beginning to become more sympathetic to mental health concerns, such as societal transitions after $9 / 11$, decreasing stigma overall about mental health and trauma, past fights with psychiatry being further away (e.g., today's authors and artists are no longer being mentored by people who were directly affected by Wertham), and new generations of writers and artists being more aware of the impact of their work beyond mere entertainment [23-25]. For example, the writer for The Unstoppable Wasp consulted with mental health professionals in order to better represent and respect people with the condition [25].

Although it is unlikely that the comic book industry will ever fully relinquish the trope of the evil or self-absorbed psychiatrist given how ingrained aspects of this presentation are, it is possible for better collaboration between the mental health field and the comic book industry to occur. Collaborations can help reduce stigma and hopefully educate the lay public and health professionals about mental health and treatments. New characters like the Unstoppable Wasp can be created and older characters can have their stories presented in such a way to at least provide some balance. If positive messages are to be portrayed by the comic book industry, mental health professionals and comic creators need to work together to allow creatives to tell compelling stories while at the same time not needlessly stigmatizing mental health patients and providers. This collaboration has already begun, and can be done.

\section{Compliance with Ethical Standards}

Disclosure On behalf of all authors, the corresponding author states that there is no conflict of interest.

\section{References}

1. The DC Comics encyclopedia: the definitive guide to the characters of the DC Universe All new edition. Editor Cefn Ridout. Penguin Random House publishing. New York 2016Hopson J.
2. Hopson J. The demonisation of psychiatrists in fiction (and why real psychiatrists might want to do something about it). Psychiatric Bulletin. 2014; 38: 175-179.

3. Testimony of Dr. Fredric Wertham, Psychiatrist, Director, Lafargue clinic, New York, Before the Senate Judiciary Subcommittee on Juvenile delinquency. Wednesday April 21st, 1954. https://www. thecomicbooks.com/wertham.html accessed December 262019

4. Day TR, Hall RCW. Déjà vu: from comic books to video games: legislative reliance on "soft science" to protect against uncertain societal harm linked to violence v. the first amendment. Oregon Law Review. 2010;89:415-52.

5. Alverson B. NYCC insider sessions powered by icv2: a demographic snapshot of comics buyers: who is buying what, and where? ICV2 Oct 19,2017 https://icv2.com/articles/news/ view/38709/nycc-insider-sessions-powered-icv2-a-demographicsnapshot-comics-buyers accessed March 24, 2020

6. Citrome L. Summer reading: medicine, psychoanalysis and the zombie apocalypse in comic books. Int J Clin Pract. 2018;72: e13221.

7. Friedman SH, Hall RCW. Teaching psychopathology in a galaxy far, far away: the light side of the force. Acad Psychiatry. 2015;39: $719-25$.

8. Marston W. Why $100,000,000$ Americans read comics. Am Scholar. 1943;13:35-44.

9. Richard, O. Don't laugh at the comics. Family Circle. Oct 251940.

10. Bender L, Lourie RS. The effect of comic books on the ideology of children. Am J Orthopsychiatry. 1951;11:540-50.

11. Testimony of Dr. Lauretta Bender, Senior Psychiatrist, Bellevue Hospital, New York, N. Y. Before the Senate Judiciary Subcommittee on Juvenile delinquency. Thursday April 22nd, 1954. https://www.thecomicbooks.com/bender.html accessed December 262019

12. American Psychological Association. Today's superheroes send wrong image to boys, say researchers: 'macho' masculine stereotype not healthy for relationships. Published August 15, 2010. https://www.apa.org/news/press/releases/2010/08/machostereotype-unhealthy accessed on January 13, 2020

13. [no author] How Iron Man introduced comic book readers to the horrors of alcoholism. NewsASANA. 2018, October 15. https:// asanarecovery.com/how-iron-man-introduced-comic-bookreaders-to-the-horrors-of-alcoholism/ accessed December 262019

14. Nierstedt, E. 10 mental health problems superheroes suffer. Published May 26, 2018 https://comicsverse.com/10-mentalhealth-problems-superheroes/ accessed December 262019

15. Liu C, Romeus L, Hall RCW. 13 reasons why and media's interest in suicide. AAPL Newsletter. 2020; 45:11, 25.

16. Sergi J. Tales from the code: Spidey fights drugs and the Comics Code Authority. Published July 18.2012. http://cbldf.org/2012/07/ tales-from-the-code-spidey-fights-drugs-and-the-comics-codeauthority/ accessed December 26, 2019

17. Amazing Spiderman Vol 1 issue 96 Marvel publishing May 1, 1971 https://www.marvel.com/comics/issue/6919/the_amazing_spiderman 1963 96 accessed January 13, 2020

18. Amazing Spiderman Vol 1 issue 13 Marvel publishing June 10, $1964 \mathrm{https}: / /$ www.marvel.com/comics/issue/6516/the_amazing spider-man_1963_13 accessed January 13, 2020

19. Marvel. available at https://www.marvel.com/characters/docsamson. Accessed 2/12/2020

20. Friedman SH, Hall RCW. Deadly and dysfunctional family dynamics: when fiction mirrors fact. Welcome to Arkham Asylum: Essays on Psychiatry and the Gotham City Institution. Edited by Sharon Packer, MD and Daniel Fredrick. McFarland Publishers. 2019, p. 65-75.

21. Friedman SH, Cerny CA. From Hannibal Lecter to Alex Cross: forensic mental health experts in popular fiction. Academic Psychiatry. 2013;37:345-51. 
22. Monahan J, Steadman J, Silver E, et al. Rethinking risk assessment: the MacArthur study of mental disorder and violence. Oxford University Press. 2001.

23. Garrett E. "Heroes In Crisis" vs "Unstoppable Wasp" and a look at mental illness. Speed force Published April 25, 2019 https:// speedforce.org/2019/04/heroes-in-crisis-vs-unstoppable-wasp/ accessed Jan 132020

24. Hoffman C. Marvel's Silk explored trauma, and became great in the process. Published on CBR May 052017 https://www.cbr.com/ marvel-silk-trauma-robbie-thompson-tana-ford/ accessed December 262019

25. Forbes E. The Unstoppable Wasp: fighting bipolar \& bad guys. https://www.bphope.com/nadia-pym-marvel-superhero/ accessed December 262019

Publisher's Note Springer Nature remains neutral with regard to jurisdictional claims in published maps and institutional affiliations. 